\title{
Specific Anaerobic Fluidized Bed Bioreactors as Pretreatment to Microfiltration in Domestic Wastewater Treatment for Reuse
}

\author{
W. Xing ${ }^{1}$, W. S. Guo ${ }^{2}$, H. H. Ngo ${ }^{3}$, A. Listowski ${ }^{4}$ \& P. Cullum ${ }^{5}$ \\ ${ }^{1,2 \& 3}$ Faculty of Engineering, University of Technology, Sydney (UTS), PO Box 123, Broadway, NSW 2007, \\ Australia \\ ${ }^{4}$ Sydney Olympic Park Authority, 7 Figtree Drive, Sydney Olympic Park, NSW 2127, Australia \\ ${ }^{5}$ Activated Carbon Technologies Pty, PO Box 50, Eltham, VIC 3095, Australia
}

\begin{abstract}
Practical use of an anaerobic granular activated carbon (GAC) fluidized bed bioreactor (FBBR) as pretreatment to microfiltration was experimentally verified. A nature starch based cationic flocculants (GF) was employed in this study for testifying its impact on the performance of GAC-FBBR. The GAC-FBBR with and without addition of GF was evaluated in terms of dissolved organic carbon (DOC) removal from biologically treated sewage effluent (BTSE). With only a daily addition of $200 \mathrm{mg}$ GF to GAC- FBBR and a depth of GAC of $500 \mathrm{~mm}$, the biomass of GAC increased from $1.5 \mathrm{~g} / \mathrm{L}$ to $4.2 \mathrm{~g} / \mathrm{L}$ within operation period of 30 days while the system resulted in $5 \%$ better DOC removal. The results indicate that the GAC-FBBR as pretreatment could effectively remove the dissolved organics and improve the critical flux. Compared with the critical flux of BTSE with submerged microfiltration (SMF) alone $\left(20 \mathrm{~L} / \mathrm{m}^{2} . h\right)$, the pretreatment by GAC-FBBR successfully increased the critical flux to $30 \mathrm{~L} / \mathrm{m}^{2}$.h. Moreover, the addition of GF into GAC-FBBR could help in raising the critical flux to $35 \mathrm{~L} / \mathrm{m}^{2}$.h.
\end{abstract}

Keywords: Specific anaerobic fluidized bed bioreactor, green flocculant, pretreatment, wastewater treatment, critical flux

\subsection{INTRODUCTION}

Membrane technology such as microfiltration (MF) and ultrafiltration (UF) has been developed as one of the reliable treatment methods for removing dissolved, colloidal and particulate pollutants from wastewater [1]. However, it has some limitation. Besides the high operation cost, membrane fouling is major obstacle for the widespread application of this technology. Membrane fouling can cause significant flux decline or trans-membrane pressure (TMP) increase and lead to higher energy required [2]. To control the membrane fouling and maintain sustainable operation, the concept of critical flux was introduced by Field et al. [3]. It is defined that critical flux as the flux for which fouling first

\#Correspondence to: H. H. Ngo (email: h.ngo@uts.edu.au) occurs (it is the maximum flux for which no fouling occurs). Below the critical flux, no multilayer deposit covers the membrane surface and the selectivity of the membrane processes is always controlled by membrane. Above the critical flux, a deposit can act as a new separator resulting in a change in selectivity. Thus, the membrane process can be operated under critical filtration conditions to keep the original separative quality of the membrane. Even though membrane fouling is an inevitable phenomenon during membrane filtration, it can be minimized by different strategies such as cleaning, appropriate membrane selection and choice of operating conditions [4]. Furthermore, the pretreatment technologies are an effective way for improving the filtration performance of the membrane and minimizing membrane fouling $[5,6]$. 
Climate change, the continued drought and population growth are putting constant pressure on existing water supplies. This means that there is a need to look for sources other than rainfall to meet future demand. Thus, wastewater reuse has been explored as options to secure water supplies. Wastewater can be reused for non-potable purpose such as agriculture, gardens, landscape and toilet flushing etc. [7]. In order to achieve the quality of reused wastewater, the membrane system is employed as the final stage of treatment and incorporated with some pretreatments. The previous study showed that the combined system of PAC adsorption, $\mathrm{FeCl}_{3}$ flocculation and UF was successfully used for municipal wastewater treatment to obtain the high quality recyclable water [8]. In addition, the biological and membrane hybrid system is also efficient process for wastewater reuse. The effluent from anaerobic biofilter and UF combined system had the COD concentration of permeates within $5-8 \mathrm{mg} / \mathrm{L}$, which could meet the reused water criteria [9]. Membrane technology can also be implemented as post-treatment of biological process to remove the suspended pollutants and pathogens from biological treated sewage effluent (BTSE) for wastewater reuse [10].

-Fluidized bed bioreactor (FBBR) has attracted growing attention as a techno-economical treatmènt system for eliminating organic pollutants from wastewater. Previous researches have shown various advantages of FBBR, such as high sludge activity, low hydraulic retention times, no clogging of reactors and small space required. Granular activated carbon (GAC) is one of the most ideal supporting media for FBBR as it has a strong affinity for attaching organic substances thus offering an ideal environment for enhanced biodegradation. In GAC-FBBR, the adsorbed organics are biodegraded by microorganisms attached on GAC and release the active sites which allow the further adsorption [11]. Fernandez et al. [12] evaluated the performance of anaerobic GAC-FBBR for distillery wastewater treatment. The COD removal efficiency stayed stable around $75 \%$ with the obtained concentration of $8 \mathrm{~g} / \mathrm{L}$ during the operation period of 120 days. Similarly, Maloney et al. [13] employed a pilot-scale anaerobic GAC-FBBR to investigate organic matter removal from pink water. It resulted in high organics removal efficiency $(>90 \%)$. This study also developed the cost estimation for this FBBR. For the purpose of the cost comparison, the cost of GAC-FBBR was approximately half of that of conventional GAC adsorption system. Therefore, GAC-FBBR is an economical friendly process for wastewater treatment.

Biodegradability of flocculant is one of the most environmental important aspects of the environmental behavior as they cause less ecological problems in the long term than a persistent one while providing carbon source for the microbial activities. In this study, one of the nature starch based cationic flocculant named Greenfloc (GF) was used to enhance the performance of GAC-FBBR. As a biodegradable flocculant, GF can provide carbon source for microorganism growth while acting as a flocculant in flocculation process. The performance of GAC-FBBR with and without addition of GF was compared in terms of biomass growth and dissolved organic carbon (DOC) removal. Meanwhile, the effects of two different FBBRs as pretreatment to a submerged microfiltration (SMF) system were evaluated using critical flux as indicator. In addition, the molecular weight (MW) distributors of BTSE and pretreated BTSE were also analyzed.

\subsection{METHODS}

\subsection{Materials}

\subsubsection{Biologically Treated Sewage Effluent (BTSE)}

Table 1 shows the composition of BTSE used in this study. It is the representative of the effluent from biological treatment and contains persistent organics such as humic acid, tannic acid, lignin, polysaccharide and other high molecular carbohydrates. The average DOC concentration of synthetic BTSE is about $10 \mathrm{mg} / \mathrm{L}$.

\subsubsection{GAC Used}

The coal based GAC (ACTICARB GS1300) provided by Activated Carbon. Technologies Pty 
Table 1 Composition of BTSE used

\begin{tabular}{ll}
\hline Compound & $\begin{array}{l}\text { Concentration } \\
(\mathrm{mg} / \mathrm{L})\end{array}$ \\
\hline Beef extract & 1.8 \\
Peptone & 2.7 \\
Humic acid & 4.2 \\
Tannic acid & 4.2 \\
(Sodium) lignin sulfonate & 2.4 \\
Sodium lauryle sulphate & 0.94 \\
Acacia gum powder & 4.7 \\
Arabic acid (polysaccharide) & 5 \\
$\left(\mathrm{NH}_{4}\right)_{2} \mathrm{SO}_{4}$ & 7.1 \\
$\mathrm{~K}_{2} \mathrm{HPO}_{4}$ & 7 \\
$\mathrm{NH}_{4} \mathrm{HCO}_{3}$ & 19.8 \\
$\mathrm{Trace} \mathrm{nutrient}_{\mathrm{MgSO}_{4} \cdot 3 \mathrm{H}_{2} \mathrm{O}}$ & \\
$\mathrm{CaCl}_{2} \cdot 2 \mathrm{H}_{2} \mathrm{O}$ & 0.71 \\
$\mathrm{MnCl}_{2} \cdot 4 \mathrm{H}_{2} \mathrm{O}$ & 0.0184 \\
$\mathrm{ZnSO}_{4} \cdot 7 \mathrm{H}_{2} \mathrm{O}$ & 0.01375 \\
$\mathrm{FeCl}_{3}$ & 0.022 \\
$\mathrm{CuSO}_{4} \cdot 5 \mathrm{H}_{2} \mathrm{O}$ & 0.0725 \\
$\mathrm{CoCl}_{2} \cdot 6 \mathrm{H}_{2} \mathrm{O}$ & 0.01995 \\
$\mathrm{Na}_{2} \mathrm{MoO}_{4} \cdot 2 \mathrm{H}_{2} \mathrm{O}$ & 0.021 \\
\hline & 0.063 \\
\hline
\end{tabular}

Ltd, Australia was used in this study. This coal based GAC has a surface area of $>1100$ BET $\mathrm{m}^{2} / \mathrm{g}$, an iodine number of $>1100 \mathrm{mg} /$ (g.min) and maximum ash and moisture contents of $10 \%$ and $3 \%$ respectively. Prior to use in experiments, fresh GAC was acclimatized to the synthetic wastewater in a $10 \mathrm{~L}$ aeration tank. As soon as the biomass attached on GAC reached the steady phase, these acclimatized GAC was used in the FBBR.

\subsubsection{NaturaI Starch Based Cationic Flocculant}

A natural starch based cationic flocculant GF provided by 2002 Research, Development and Consulting Ltd., Hungary was selected as a representative of naturally occurring based bioflocculant in this study. The components of this flocculant includes cationic starch ether (16.7 wt\%), sodium metabisulfite preservative $(<0.5 \mathrm{wt} \%)$ and water (to $100.0 \mathrm{wt} \%)$. It is completely soluble in water with a density of $1050 \mathrm{~kg} / \mathrm{m}^{3}$.

\subsection{Experimental}

\subsubsection{GAC-FBBR}

Two laboratory-scale anaerobic GAC-FBBRs with $1200 \mathrm{~mm}$ tall and $25 \mathrm{~mm}$ inner diameter were employed. $200 \mathrm{~mL}$ of acclimatized GAC with biomass of $1.5 \mathrm{~g} / \mathrm{L}$ was added in each FBBR to have an actual (non-fluidized) filter depth of $500 \mathrm{~mm}$. BTSE was fed at a flow rate of 14.4 L/day through a FBBR with the HRT of 20 minutes whilst fluidization of GAC was achieved through recycling the effluent from near the top to the bottom assembly. An amount of $200 \mathrm{mg}$ GF was daily added.to one of the GAC-FBBRs. Samples of BTSE and the effluents from GACFBBRs were taken and filtered through $0.45 \mu \mathrm{m}$ filter prior to analyzing DOC and determining the molecular weight (MW) distribution.

\subsubsection{Submerged Microfiltration (SMF) Hybrid System}

The schematic diagram of the submerged microfiltration (SMF) hybrid system set-up is shown in Figure 1. The hydrophilic polyethylene hollow fiber microfiltration membrane with pore size of $0.1 \mu \mathrm{m}$ and surface area of $0.05 \mathrm{~m}^{2}$ was used (Table 2). The BTSE or the effluent from GACFBBR was delivered to the membrane reactor by a feeding pump, and the compressed air was supplied to the membrane reactor with the flow rate of $8 \mathrm{~L} / \mathrm{min}$. The permeate flow rate was controlled by a suction pump. Flux-step method was applied to determine the critical flux [14]. With the synthetic BTSE or pretreated BTSE, the flux-step experiments were carried out at a step height of $5 \mathrm{~L} / \mathrm{m}^{2} . \mathrm{h}$ and duration of 60 mins with the initial flux of $10 \mathrm{~L} / \mathrm{m}^{2} . \mathrm{h}$. When the filtration period was finished (after 60 mins), the membrane was backwashed with the distilled water at the flux of $30 \mathrm{~L} / \mathrm{m}^{2}$.h for $1 \mathrm{~min}$. After each experiment, the membrane was chemically cleaned by firstly immersed in $1 \% \mathrm{HCl}$ solution for 2 hours to remove the calcium. The membrane was then submerged in $2 \%$ citric acid for 2 hours to remove iron, aluminum and manganese attachments from the membrane. Finally, the membrane was submerged in $0.4 \% \mathrm{NaOCl}$ and $4 \% \mathrm{NaOH}$ solution for 2 hours to remove silica and organic matter. 


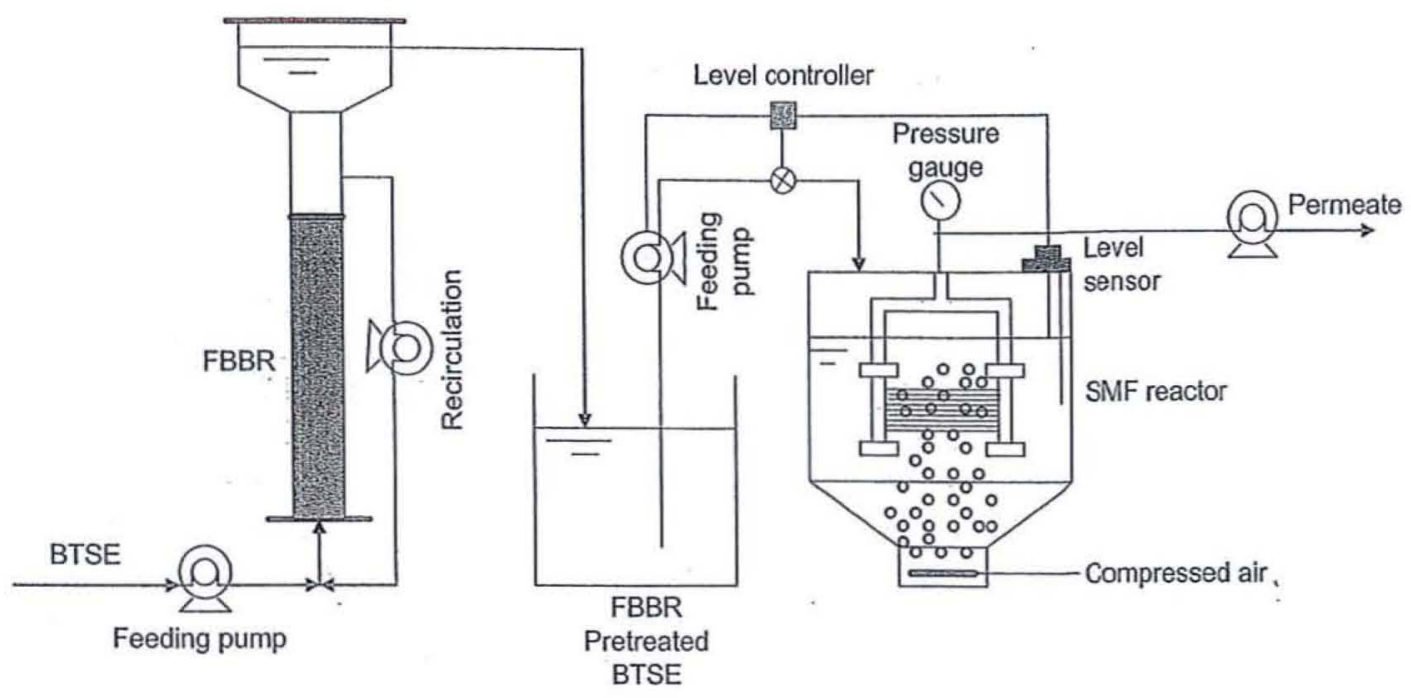

Figure 1 Schematic diagram of the FBBR submerged microfiltration (SMF) hybrid system

Table 2 Characteristics of the hollow fibre membrane module used

\begin{tabular}{ll}
\hline Item & Characteristics \\
\hline Material & $\begin{array}{l}\text { Hydrophilic } \\
\text { polyethylene }\end{array}$ \\
Nominal pore size & $0.1 \mu \mathrm{m}$ \\
Outer diameter & $0.41 \mathrm{~mm}$ \\
Inner diameter & $0.27 \mathrm{~mm}$ \\
No. of fibre & $320(16 \times 20)$ \\
Length of fibre & $12 \mathrm{~cm}$ \\
Surface area & $0.05 \mathrm{~m}^{2}$ \\
Membrane packing density & $9858 \mathrm{~m}^{2} / \mathrm{m}^{3}$ \\
Membrane manufacturer & Mitsubishi-Rayon, \\
& Tokyo, Japan \\
\hline
\end{tabular}

\subsection{Analysis}

DOC concentration of water sample was measured using Analytikjena Multi N/C 2000 analyzer. The biomass (monitored as mixed liquor volatile suspended solid, MLVSS) was measured by APHA Standard Method [15]. High pressure liquid chromatography (HPLC, Jasco, Japan) and protein column (Protein-pak 125, Water Milford, USA) were used to determine the MW distribution.

\subsection{RESULTS AND DISCUSSION}

\subsection{Performance of GAC-FBBR}

The performances of the GAC-FBBRs in terms of DOC removal are presented in Figure 2. The results indicate that GAC-FBBR with addition of GF (GF-GAC-FBBR) resulted in 5\% better organic matter removal during the operation period of 30 days. In the first three days, both of GAC-FBBR and GF-GAC-FBBR led to almost the same DOC removal efficiency. However, after that GF-GAC-FBBR began to perform better and remained its superiority for the rest of a 30-day operation. From the 18 th day, both of GAC-FBBRs performed stable and resulted in approximately $\geq 55 \%$ DOC removal. In addition, the results also showed that the biomass of GAC in GAC-FBBR remained at $1.5 \mathrm{~g} / \mathrm{L}$ within operation period while that of GAC in GF-GACFBBR increased to $4.2 \mathrm{~g} / \mathrm{L}$. It can be explained that as $1 \mathrm{~g} / \mathrm{L}$ GF contains $455 \mathrm{mg} / \mathrm{L}$ total carbon (TC), it can provide extra carbon source to help the microorganism growth. Based on the previous studies, the addition of carbon source is very necessary for the biomass growth in the anaerobic FBBR operation $[16,17]$. Hence, as an effective carbon source, GF is not only helpful for biomass growth but also improves the organic removal efficiency of GAC-FBBR. 


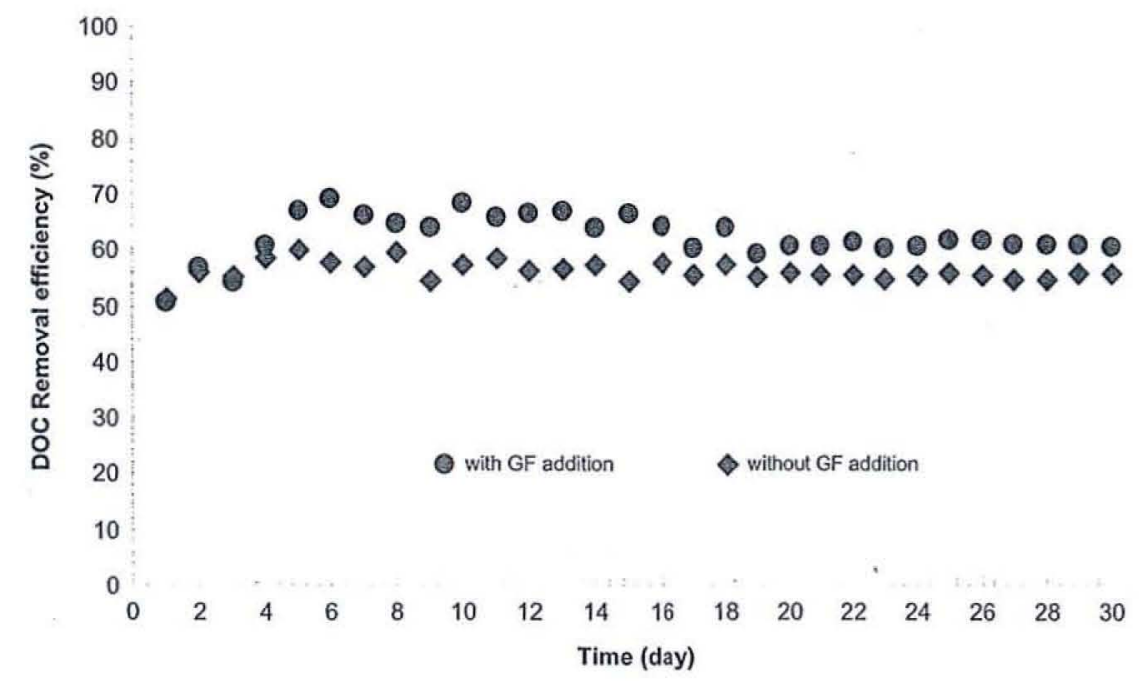

Figure 2 Performance of GAC-FBBR with and without GF addition (depth $=500 \mathrm{~mm}$, average initial $\mathrm{DOC}=10 \mathrm{mg} / \mathrm{L})$

\subsection{Performance of GAC-FBBR as Pretreatment to SMF}

-The performance of GAC-FBBR with and without addition of GF as pretreatment to SMF was evaluated in terms critical flux. Figures 3 (a), 3 (b) and 3 (c) show the critical flux of membrane with BTSE without pretreatment, GAC-FBBR and GFGAC-FBBR pretreated BSTE. For the synthetic BTSE without pretreatment, TMP appeared constant for the filtration flux up to $20 \mathrm{~L} / \mathrm{m}^{2} . \mathrm{h}$ while its rate began to increase at higher filtration flux due to membrane fouling. The critical fluxes were found to be $30 \mathrm{~L} / \mathrm{m}^{2} . \mathrm{h}$ and $35 \mathrm{~L} / \mathrm{m}^{2}$.h for GAC-FBBR and GF-GAC-FBBR respectively. Thus, the FBBR as pretreatment could remove the dissolved organics and improve the critical flux effectively. Although the DOC is not typically retained by MF due to the pore size involved being much larger component molecules, DOC is nevertheless involved in both short and long term membrane fouling [18]. Therefore, removing DOC from BTSE by GAC-FBBR is helpful to reduce membrane fouling. In addition, after - membrane filtration, the permeate with the average DOC of $2.5 \mathrm{mg} / \mathrm{L}$ and turbidity of 0.35 NTU met the Australian wastewater recycling regulations to be reused in domestic non-potable purpose, such as toilet flushing, garden watering etc. [19].

\subsection{MW Distribution}

In order to understand the advantage of the GAC-FBBR as pretreatment to SMF, the MW distributions were analyzed based on the BTSE and the effluent from the GAC-FBBRs. The MW of the organic matter in the synthetic BTSE ranged from 273 to 36270 Daltons. Figure 4 shows the MW distributions of organic matter of the BTSE, GAC-FBBRs pretreated BTSE. Both cases of GAC-FBBRs were effective in removing the large MW organics. It indicates that GAC bioadsorption in GAC-FBBR could remove the high MW organic matter from BTSE effectively. The similar results can be found in previous study. Vigneswaran et al. [20] observed that the GAC bioadsorption in a GAC biofilter led to the adequate removal of relative high MW organic compounds. It was observed that GAC-FBBRs especially GF-GAC-FBBR almost removed high MW organics in the range between 36270 to 1200 Daltons. The main reason is that GF provides carbon source for microorganism growth while acting as a flocculant in flocculation process. GF flocculation could help in eliminating some of 


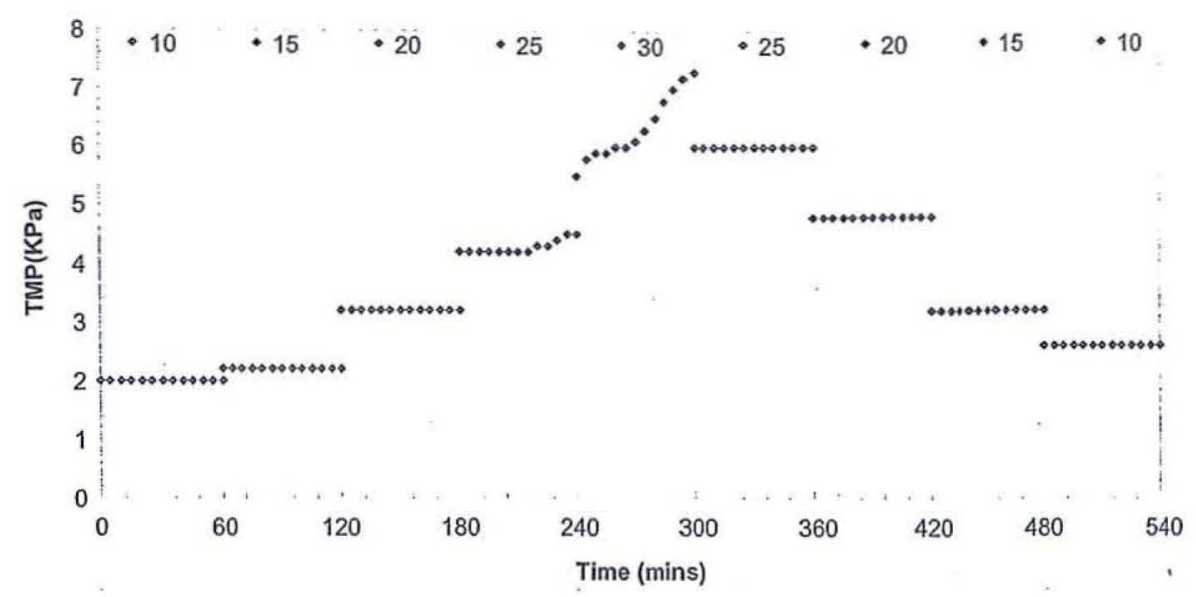

(a)

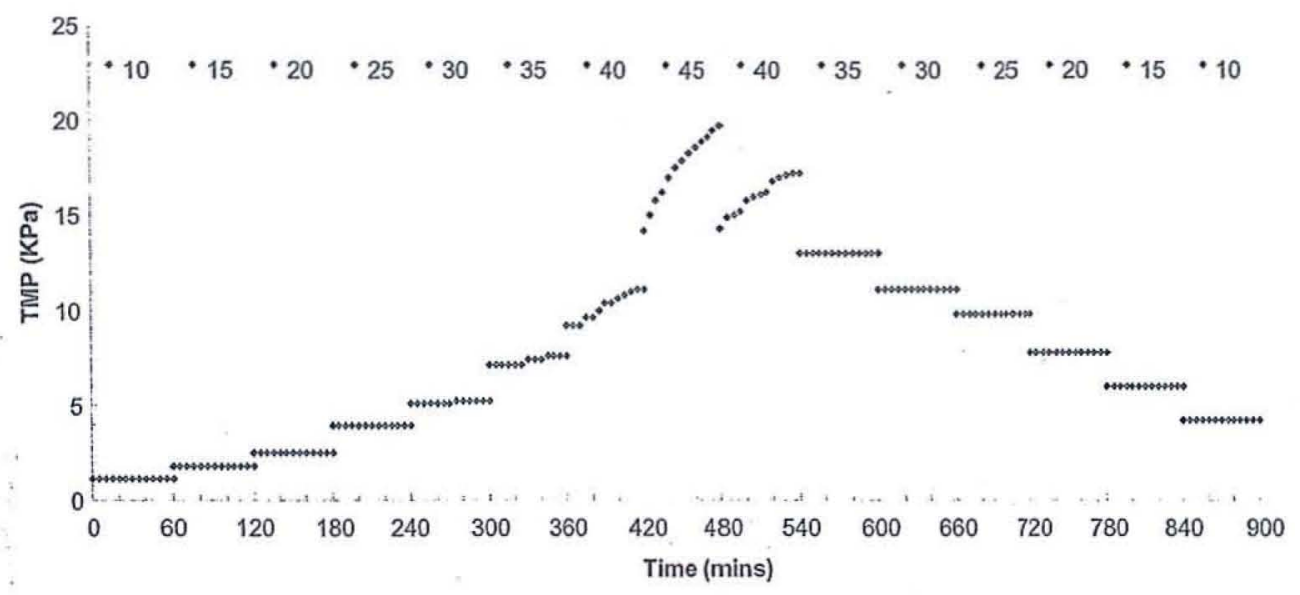

(b)

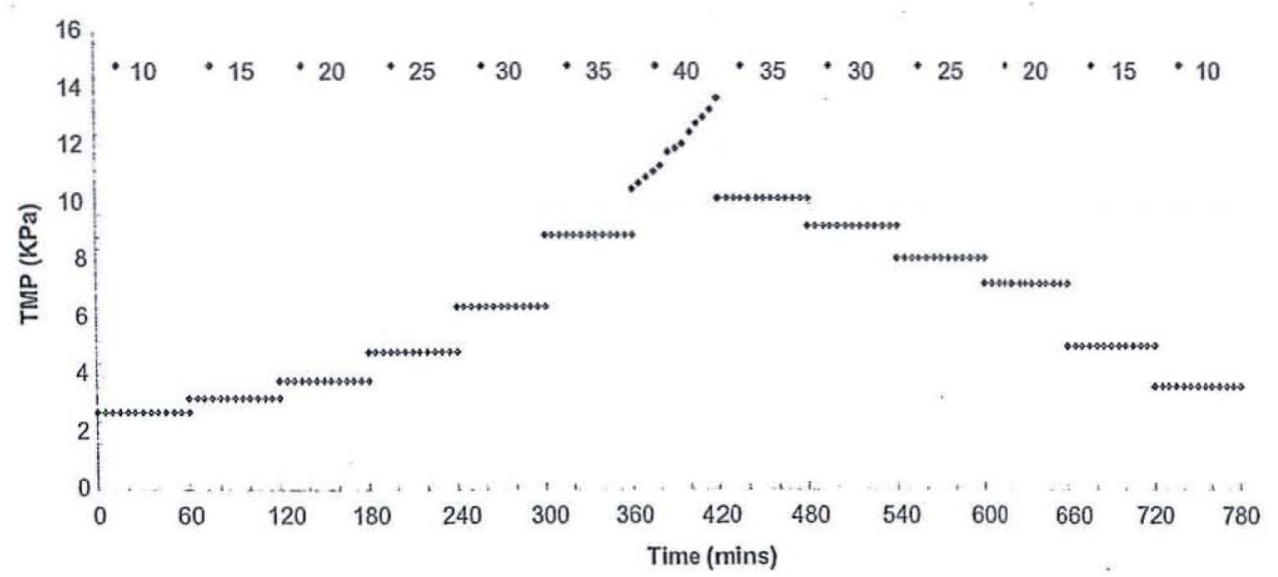

(c)

Figure 3 Effect of FBBR as pretreatment on critical flux (flux unit: $\mathrm{L} / \mathrm{m}^{2} . \mathrm{h}$; (a) BTSE without pretreatment, (b) GAC-FBBR pretreated BTSE, (c) GF-GAC-FBBR pretreated BTSE) 


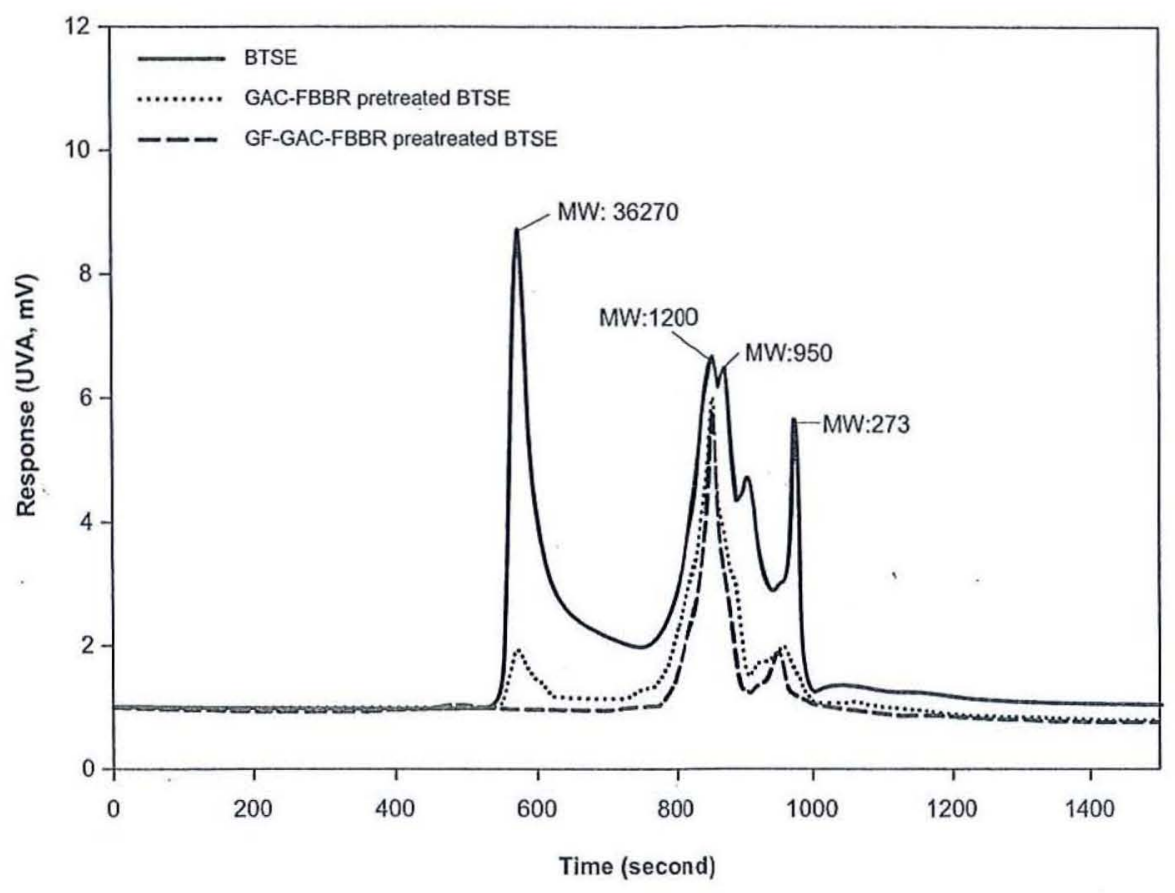

Figure 4 MW distribution of the BTSE with different FBBRs pretreatment

large MW organics from BTSE such as high MW polysaccharides. As can be seen in Figure 4, both of GAC-FBBRs were also able to remove small MW organics ( $\leq 273$ Daltons).

\subsection{CONCLUSIONS}

The use of GAC-FBBR as pretreatment to microfiltration was found to be applicable in BTSE treatment for reuse due to the following specific findings:

- Addition of GF to GAC-FBBR is helpful for biomass growth and improves the organic removal efficiency.

- GAC-FBBR as pretreatment to the MF was successful in reducing membrane fouling and increasing the critical flux. GAC-FBBR with addition of GF could increase the critical flux up to $35 \mathrm{~L} / \mathrm{m}^{2}$.h compared to that of SMF alone $\left(20 \mathrm{~L} / \mathrm{m}^{2} . \mathrm{h}\right)$.

- GAC-FBBR could effectively remove large MW organics (36270-1200 Daltons) and small MW organics ( $\leq 273$ Daltons) from BTSE.

\section{ACKNOWLEDGEMENTS}

This research was funded by ARC linkage project (LP 0775149). The authors are grateful to the support of Sydney Olympic Park Authority (SOPA) and Activated Carbon Technologies Pty Ltd. The authors also thank 2002 Research, Development and Consulting Ltd., Hungary for providing flocculant GF.

\section{REFERENCES}

[1] Guo, W.S. 2005. Microfiltration Hybrid Systems in Wastewater Treatment for Reuse. Ph.D. Thesis. University of Technology, Sydney.

[2] Pearce, G. 2007. Introduction to Membranes: Fouling Control. Filtration $\&$ Separation. 44: 30-32.

[3] Field, R.W., D. Wu, J.A., Howell, and B.B. Gupta. 1995. Critical Flux Concept for Microfiltration Fouling. Journal of Membrane Science. 100: 259-272. 
[4] Field, R., D. Hughes, Z. Cui, and U. Tirlapur. 2008. Some Observations on the Chemical Cleaning of Fouled Membranes. Desalination. 227: 132-138.

[5] Haberkamp, J., A.S. Ruhl, M. Ernst, and M. Jekel. 2007. Impact of Coagulation and Adorption on DOC Fractions of Secondary Effluent and Resulting Fouling Behaviour in Ultrafiltration. Water Research. 41: 3794-3802.

[6] Guo, W.S., S. Vigneswaran, H.H. Ngo, and H. Chapman. 2004. Experimental Investigation of Adsorption-flocculationmicrofiltration Hybrid System in Wastewater Reuse. Journal of Membrane Science. 242: 27-35.

[7] Hurlimann, A. and J. McKay. 2007. Urban Australians Using Recycled Water for Domestic Non-potable Use-An Evaluation of the Attributes Price, Saltiness, Colour and Odour Using Conjoint Analysis. Journal of Environmental Management. 83 (1): 93-104.

[8] Goren, U., A. Aharoni, M. Kummel, R. Messalem, I. Mukmenev, A. Brenner, and V. Gitis. 2008. Role of Membrane Pore Size in Tertiary Flocculation/Adorption/ Ultrafiltration Treatment of Municipal Wastewater. Separation Purification Technology. 61: 193-203.

[9] Khoufi, S., F. Aloui, and S. Sayadi. 2008. Pilot Scale Hybrid Process for Olive-Mill Wastewater Treatment and Reuse. Chemical Engineering and Processing: Process Intensification. (in press).

[10] Oron, G., L. Gillerman, N. Buriakovsky, A. Bick, M. Gargir, Y. Dolan, Y. Manor, L. Kartz, and J. Hagin. 2008. Membrane Technology for Advanced Wastewater Reclamation for Sustainable Agriculture Production. Desalination. 218: 170-180.

[11] Pruden, A., M. Sedran, M. Suidan, and A. Venosa. 2003. Biodegradation of MTBE and BTEX in an Aerobic Fluidized Bed Reactor. Water Science and Technology. 47(9): 123-128.

[12] Fernandez, N., F. Fdz-Polanco, S.J. Montalvo, and D. Toledano. 2001. Use of
Activated Carbon and Natural Zeolite as Support Materials, in an Anaerobic Fluidized Bed Reactor for Vinasse Treatment. Water Science and Technology. 44(4): 1-6.

[13] Maloney, S.W., N.R. Adrian, R.F. Hickey, and R.L. Heine. 2002. Anaerobic Treatment of Pinkwater in a Fluidized Bed Reactor Containing GAC. Journal of Hazardous Materials. 92: 77-88.

[14] Le Clech, P., B. Jefferson, I.S. Chang, and S.J. Judd. 2003. Critical Flux Determination by the Flux-step Method in a Submerged Membrane Bioreactor. Journal of Membrane Science. 227: 81-93.

[15] APHA. 1998. Standard Methods for the Examination of Water and Wastewater. $20^{\text {th }}$ ed. Washington, DC: American Public Health Association.

[16] Georgiou, D., and A. Aivasidis. 2006. Decoloration of Textile Wastewater by Means of a Fluidized-bed Loop Reactor and Immobilized Anaerobic Bacteria. Journal of Hazardous Materials. B135: 372-377.

[17] Saravanane, R., and D.V.S. Murthy. 2000. Application of Anaerobic Fluidized Bed Reactors in Wastewater Treatment: A Review. Environment Management and Health. 11(2): 97-117.

[18] Fabris, R., E.K. Lee, C.W.K. Chow, V. Chen, and M. Drikas. 2007. Pre-Treatments to Reduce Fouling of Low Pressure Microfiltration (MF) Membranes. Journal of Membranes Science. 289: 231-240.

[19] EPA Victoria. 2003. Guidelines for Environmental Management - Use of Reclaimed water. EPA Victoria: Southbank, Victoria.

[20] Vigneswaran, S., H.K. Shon, J. Kandasamy, and W.G. Shim. 2007. Performance of Granular Activated Carbon (GAC) Adsorption and Biofiltration in the Treatment of Biologically Treated Sewage Effluent. Separation Science and Technology. 42: 3101-3116. 